\title{
Myocardial perfusion in humans: What can we measure?
}

\author{
Peter F Ludman, Philip A Poole-Wilson
}

Though angina suggests myocardial ischaemia, this symptom is poorly related to the extent, severity, or site of impaired myocardial perfusion. Electrocardiography during graded exercise is commonly used as a clinical tool to assess the extent and site of ischaemia but it is a poor guide. Myocardial oxygen extraction is almost maximal in the resting mammalian heart, an obligatory aerobic organ. As a result increases in oxygen requirement are met predominantly by increases in myocardial blood flow and many of the commonest cardiovascular diseases are manifest as a relative or absolute reduction in myocardial perfusion. The measurement of myocardial perfusion is the cornerstone to understanding the pathophysiological mechanisms involved.

All currently available methods for the measurement of myocardial perfusion in humans are limited. A technique should ideally provide measurements of absolute blood flow with a high degree of spatial and temporal resolution and without perturbing the circulation under investigation. In animals the use of radiolabelled microspheres allows up to nine measurements of absolute perfusion with high spatial resolution and is considered the "gold standard" of available techniques." Because of the need for tissue samples the method is inapplicable to human studies. All the methods available in humans have limitations. Some do not assess absolute flow, and underestimation of high perfusion rates is a feature of many of the methods based on tracers: All have limited spatial resolution so that none can be used to assess differential perfusion in the layers of the myocardium. Improvement in spatial resolution may come with the development of techniques such as contrast echocardiography, magnetic resonance, and ultrafast $x$ ray computed tomography scanning.

All methods assess arterial inflow, venous outflow, or tissue perfusion itself. Methods based on the measurement of arterial inflow or venous drainage have the advantage of high temporal resolution, but limited spatial resolution, and are unable to quantify absolute blood flow per unit myocardial mass.

\section{Arterial inflow}

Electromagnetic flow probes rely on Faraday's law. They measure the current induced by blood (a moving conductor) in the magnetic field of the probe. Though the technique is invaluable in animal research, where a probe can be implanted to become immobilised by ingrowth of fibrous tissue, difficulties with calibration in humans have led to increasing use of a different technique with Doppler probes.

When sound waves are reflected from a moving structure a frequency shift results that is proportional to the velocity of the moving structure relative to the transmitter. With the pulsed Doppler technique a piezoelectric crystal is used to transmit and receive high frequency sound waves that are reflected from blood corpuscles. Though the angle between the ultrasound wave and blood velocity must be known, the velocity at a specified distance from the crystal can be measured. An intravascular probe was developed to measure coronary blood flow in a coronary ostium with an 8 French catheter. ${ }^{2}$ Further refinement led to the development of a Doppler probe mounted on a 3 French catheter that used a $20-\mathrm{MHz}$ pulsed Doppler signal. The probe can be introduced over a 0.018 inch guide wire to measure coronary flow velocity in individual coronary arteries. ${ }^{3}$ Even smaller probes have been developed by mounting a $12 \mathrm{MHz}$ transducer on the tip of an 0.018 inch diameter flexible steerable guide wire. This allows the measurement of velocity beyond epicardial stenoses and in more distal vessels. ${ }^{4}$ The principal disadvantage of the technique is that to calculate blood flow the cross-sectional diameter of the vessel must be known. The diameter can be measured at angiography or from ultrasound echoes, but small errors are squared in the calculation of area. The accurate measurement of vessel diameter at angiography is difficult. After biplane angiography either the edge of the vessel or its density once filled with contrast may be used as a measure of its diameter. Both these quantitative angiographic methods have been extensively studied and though they can be used to produce accurate and reproducible results they are heavily dependent on the angiographic and calibration system that is used. ${ }^{5}$ Because pulsed Doppler probes measure velocity at a specific distance from the crystal, changes in the velocity profile, including turbulence, will lead to inaccuracies in measurement of flow. When intravascular probes are used, measurements may be confounded by movement 
of the Doppler probe relative to the vessel wall and by the potential effect of luminal obstruction by the catheter. The spatial resolution of the technique is defined by the region of myocardium supplied by the artery in which the catheter is positioned, and endocardial or epicardial perfusion cannot be distinguished. Nevertheless, rapid changes in flow velocity can be assessed, making the method well suited to determining the acute effect of pharmacological agents and vessel lumen anatomy on flow velocity. ${ }^{6}$

Videodensitometry can be used to track the movement of a bolus of radiographic contrast injected into a coronary artery. The density of contrast at two sequential locations is measured to calculate the transit time. If the volume of the arterial segment between these points is determined from biplane angiography the flow can be calculated as:

$$
\text { Flow }=\frac{\text { Vascular volume }}{\text { Transit time }}
$$

Though this method allows determination of absolute flow it can only be applied to straight, proximal vessels with no branches and no overlapping vessels. Further development of videodensitometry is discussed below.

An alternative approach is to measure the expected significance of an epicardial stenosis on coronary flow. Gould proposed the concept of stenosis reserve, in which the important dimensional features of a stenosis (normal area, stenotic area, length of lesion, and entrance and exit angles) are used with a hydraulic equation to give a value for theoretical flow reserve. ${ }^{7}$ This form of analysis allows the potential impact of lesions to be assessed without being affected by variables such as heart rate, collateral flow, and loading conditions and may be useful in interventional studies where these variables are changing. Nevertheless the different physiological importance of a lesion supplying a normal left ventricular function compared, for example, with a severely hypertrophic ventricle cannot be modelled by this method. Some of the limitations of quantitative angiography have been discussed above. In the assessment of lesion morphology the development of optimal biplane imaging of coronary segments is of prime importance; the long axis of the lesion and normal vessel should be parallel to the image intensifier planes, which are also perpendicular to each other. With biplane multidirectional $x$ ray equipment, which has known geometric properties, this "triple orthogonal" alignment can be achieved by computer. $^{8}$ This approach together with improvement in digital image processing may improve the otherwise dissapointing results of lesion assessment by videodensitometry. ${ }^{910}$ Three dimensional reconstruction of lesion morphology has also been investigated to improve assessment of the physiological significance of stenoses. ${ }^{11}$

Coronary venous flow

Measurement of coronary venous drainage is relatively inexpensive and safe and allows rapid alterations in flow to be detected. The spatial resolution is defined by the region of myocardium draining into the venous system sampled. Because the region is dependent on venous anatomy, absolute flow per unit muscle mass cannot be determined. It is assumed that blood flow in the great cardiac vein represents predominantly left anterior descending venous drainage. Variations in coronary sinus drainage are such that it is important that the sampling catheter is advanced to the origin of the great cardiac vein. There are numerous anastomoses within the venous system, and any measurements of coronary sinus blood within $2 \mathrm{~cm}$ of the ostium may be contaminated by right atrial blood particularly in the presence of right atrial hypertension, tricuspid valve disease, or arrhythmia. Flow in the great cardiac vein is usually measured by thermodilution or by determining venous oxygen saturation. Continuous thermodilution uses the principle that if cold saline is infused into the coronary sinus, the change in temperature downstream is proportional to the blood flow. It is assumed that the injectate is infused at a rate sufficiently rapid and through a catheter designed to ensure adequate mixing, that the catheter is insulated to minimise warming of the injectate during catheter transit, that recirculation is prevented by limiting the duration of infusion to 20 to 30 seconds, that the temperature sensors (thermistors) in the system are carefully calibrated, and finally that the position of the catheter in the coronary sinus is stable (for multiple measurements to be comparable). Initial encouraging validation studies used animal models with the catheter tied in the coronary sinus. ${ }^{12}$ This prevented changes in catheter position and hence inclusion or exclusion of additional venous draining areas. Later validation with the catheter positioned as it might in a patient showed very poor correlation with other techniques such as electromagnetic flow probes ${ }^{13}$ especially when right atrial pressure was raised.

Because myocardial oxygen extraction is near maximal at rest, changes in oxygen saturation in the coronary sinus reflect changes of coronary blood flow, provided that during the measurement period there is no change in myocardial oxygen demand, there is no significant redistribution of endocardial to epicardial blood flow, and no change in contractility. From the Fick principle:

\section{Coronary blood flow $=$ Myocardial oxygen demand Arteriovenous oxygen content difference}

This relatively simple method has been used to assess rapid and large changes in relative flow, where there is no requirement for a high spatial resolution. ${ }^{14}$

\section{Tissue perfusion}

Myocardial perfusion can be measured directly by injecting a tracer into the circulation and measuring its concentration in the 
myocardium. The characteristics of the methods used are governed by the tracer used, the detection system, and the mathematical model applied to the measurements in order to derive perfusion.

\section{MATHEMATICAL MODELS}

Most perfusion measurements are based on one of two mathematical models:

\section{First pass distribution}

The Sapirstein principle of first pass distribution $^{15}$ states that if an indicator is injected into the circulation the total amount of indicator delivered to each tissue during the first transit is proportional to the flow to that tissue. An ideal indicator would flow to the tissues and then remain trapped there on first transit (which can be considered as $100 \%$ extraction of tracer by the tissue) so that the total amount reaching each tissue could be measured. This is the basis of flow measurement by radiolabelled microspheres.

Measurement of the relative numbers of microspheres in different regions of tissue allows calculation of the relative blood flow (BF) to those regions.

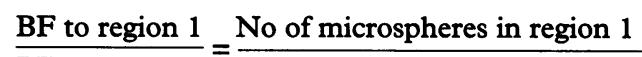
$\frac{\mathrm{BF} \text { to region } 2}{\text { No of microspheres in region } 2}$

If the absolute flow to region 2 is known (from an independent measurement technique), then absolute flow to all other regions can be calculated. One method is to use a surrogate organ. During the flow measurement, blood is withdrawn by pump at a constant known rate into a syringe. ${ }^{1}$ The number of microspheres in the syringe can be measured and the equation solved.

Techniques relying on first pass distribution, sometimes with minor modifications, include thallium-201 scintigraphy, positron emission scanning (with some tracers), and ultrafast $x$ ray computed tomography with intravenous radiographic contrast as a tracer.

Unlike microspheres most tracers used in humans show variable extraction, which is high at low flow but falls as flow increases. Thallium is an example: at moderate flow rates it is distributed intracellularly within the myocardium in proportion to regional blood flow but at low flow it exceeds the microspheres and at high flow the extraction fraction falls. ${ }^{16}$ Because the method only allows measurement of relative perfusion this feature is of less clinical significance than in positron emission tomography, where there is the potential to measure absolute flow. The first pass extraction of both ${ }^{13} \mathrm{~N}$-ammonia ${ }^{17}$ rubidium- $82^{18}$ falls as flow increases (from about $70 \%$ to $35 \%$ and $55 \%$ to $30 \%$ respectively) and for this reason both tend to underestimate flow rates above 2.0 and $2.5 \mathrm{ml} / \mathrm{g} / \mathrm{min}$ for ${ }^{13} \mathrm{~N}$ ammonia and rubidium-82 respectively. ${ }^{18} \mathrm{~A}$ further disadvantage is that the extraction of both these tracers may be affected by metabolic changes in the myocardium. Radiographic contrast is also extracted in a flow dependent fashion ${ }^{19}$ which is probably the predominant factor in the underestimation of flow rates by ultrafast computed tomography above about 1.5 $\mathrm{ml} / \mathrm{g} / \mathrm{min}$. Modifications to the basic mathematical model, taking into account tracer kinetics and extraction fraction, have been used to improve flow measurement at high perfusion rates. ${ }^{20} 21$

In contrast ${ }^{15} \mathrm{O}$-labelled water is a diffusible tracer with an extraction fraction that seems to be independent both of flow rate and the metabolic state of the myocardium. ${ }^{22}$ Though there are other difficulties with this method (because the tracer also labels the blood pool), accurate measurements of perfusion have been performed over a wide range of flows using a diffusible tracer model (below).

\section{Diffusible tracer techniques}

These techniques depend on the physical properties of inert gases. Being small and highly lipid soluble the atoms diffuse rapidly across capillary walls so that the rate of exchange between blood and tissue can be assumed to be limited by blood flow. There have been two approaches to the measurement of perfusion. The first method requires the measurement of tracer concentration in the arterial inflow and venous outflow of the organ under investigation. ${ }^{23}$

If an inert gas is introduced into the systemic circulation the arterial content will rise faster than the venous concentration because of absorption from the circulating compartment (saturation phase). If the input ceases after the heart is fully saturated with the inert gas the arterial concentration will fall faster than the coronary sinus concentration, because the gas will continue to diffuse back into the venous system (desaturation phase). From the Fick principle it can be shown that either during the saturation or desaturation phase, the integrated difference in gas concentration between the arterial input and venous outflow is proportional to coronary flow per unit weight. ${ }^{24}$ Several criteria have to be met. The indicator must be physiologically inert and must saturate the myocardium evenly, its partition coefficient in myocardium, fat, red blood cells, and plasma must be known, venous blood must be sampled from the entire myocardial region of interest, coronary flow must be stable during the saturation and desaturation phase (5 to 20 minutes), and data from the entire time course (until saturation or desaturation is 98 to $99 \%$ complete) must be analysed. The only method currently used to measure myocardial perfusion in humans involves the inhalation of a non-radioactive inert gas (helium, hydrogen, or argon) with measurements of arterial and coronary sinus concentrations by gas chromatography. The method cannot be used to assess regional heterogeneity of flow and can therefore only be used where myocardial perfusion is assumed to be homogeneous, as in patients with left ventricular hypertrophy. Coronary sinus blood is sampled and therefore assumed to drain only left ventricular blood. The time required for each measurement is long and flow must 
remain constant during this time. Finally the technique has only been validated for flow up to $1.6 \mathrm{ml} / \mathrm{min} / \mathrm{g}$. ${ }^{25}$ Nevertheless the method has been widely used because, though there are limitations, it is able to measure flow per unit mass in the left ventricle.

The second approach, also referred to as "residue detection", is also based on the Fick principle but has the advantage that flow can be derived without resort to blood sampling, provided that the rate of change of concentration of tracer in the tissue can be measured by an external detector. ${ }^{26}$ Flow is calculated from the mono-exponential rate constant of clearance from the muscle after a bolus injection of dissolved inert gas tracer. Though this derivation resembles the first, ${ }^{24}$ it makes the additional assumption that the fractional rate of change of venous inert gas concentration is constant throughout desaturation. By using a multiple crystal scintillation camera and recording the rate of washout from multiple discrete regions of myocardium after intracoronary injection of xenon-133, spatial resolution can be added to the technique. ${ }^{27}$

The high lipid solubility of xenon limits the accuracy of repeated measurements. Planar image acquisition may result in superimposition of normal and underperfused myocardium and does not allow assessment of transmural flow heterogeneity. In regions where there is tissue inhomogeneity (such as scar tissue and residual viable myocardium) flow is weighted in favour of high flow areas. ${ }^{28}$ As with non-radioactive gas clearance, validation studies show that measurements of flow rates is limited up to only $2 \mathrm{ml} / \mathrm{min} / \mathrm{g} .{ }^{29}$ Modifications of this model have been used with positron emitters such as ${ }^{15} \mathrm{O}$-labelled water.

Other models: videodensitometry

With the wide availability of coronary angiography and the recent introduction of digital acquisition systems, there has been much interest in the development of videodensitometric methods to measure coronary flow and myocardial perfusion. Several other mathematical models have been explored, some being based on those described above. Overall there have been five different approaches. Though the first two methods involve the assessment of contrast in epicardial coronary vessels and the last three assessment of contrast in the myocardium they are grouped in this section for clarity.

Transit time-The principles of this method are described in the section entitled "arterial inflow". The requirement for a non-branching, straight proximal vessel with no overlapping structures is so limiting that several adaptations have been investigated that overcome some of the methodological problems. The wavefront (rather than mean) transit time has been used to make measurements before blood flow is perturbed by contrast dilating coronary resistance vessels and to avoid effects of variable washout from myocardium. ${ }^{30}$ Densitometric measurements have also been used to assess vessel volume. ${ }^{31}$
More recently encouraging results have been reported with three dimensional reconstruction of the coronary anatomy from biplane angiography (see later under "linear programming techniques"). This allows accurate measurements of coronary intravascular volume by reducing inaccuracies caused by the foreshortening resulting from vessel tortuosity. When combined with an assessment of transit time, measurements of absolute flow have been recorded in the left anterior descending coronary artery of humans. ${ }^{32}$ In general, in the assessment of absolute flow some correction is necessary for the exponential relation between iodine concentration and $x$ ray attenuation as well as for $x$ ray scatter, veiling glare, and pincushion distortion. Most of these techniques also require a high frame rate of image acquisition.

Indicator dilution-An alternative approach was proposed by Foerster et $\mathrm{al}^{33}$ based on the principles of indicator dilution. The area under the curve of contrast density plotted against time is measured for an epicardial coronary artery by subtracting the opacification of overlying myocardium. Flow is inversely related to this area and directly related to the amount of contrast given. If measurements are made under both basal and hyperaemic conditions then, provided an identical region of interest is used and factors relating to calibration (such as the relation between contrast mass and the density on the image intensifier) are unchanged, the ratios of basal to hyperaemic flow can be found.

These methods involve sub-selective contrast injection of a precisely known contrast volume that must be constant for repeated injections. They also require electrocardiographically triggered image acquisition and contrast injection and good registration of subtracted images. More recently investigators have attempted to improve the applicability of the technique by obviating the need for a predetermined power injected bolus of contrast. $^{34}$ Nevertheless, the methodological problems preclude the routine use of these techniques during diagnostic coronary arteriography.

Appearance time-Digital radiographic techniques have been used to enhance image quality and measurements of regional flow have been developed based on the myocardial "blush" of contrast that follows intracoronary injections. ${ }^{35}$ The myocardial contrast appearance time (MCAT) is defined as the interval between onset of electrocardiographically triggered contrast injection to the point at which the density in a myocardial region of interest reaches a certain percentage of the maximum. The method underestimates the flow reserve measured by an electromagnetic flow probe, ${ }^{36}$ and has therefore been modified to include not only a measure of transit time (MCAT) but also a measure of the maximum contrast density in a region of interest considered to be related to the vascular volume. This results in a much improved agreement between flow reserve measured by videodensitometry and electromagnetic flow probe. ${ }^{37}$ 
Precise image registration is required as is complete replacement of intracoronary blood by contrast.

Contrast washout analysis - The mathematical model used for inert gas clearance (described above) has also been applied to the washout of myocardial contrast after intracoronary injection in humans. ${ }^{38}$ Digital subtraction was used to enhance measurements of myocardial contrast density, with encouraging results.

Transfer function analysis - To try to overcome several limitations of the above methods, Eigler et $a l^{39}$ used a method in which they assumed that the coronary transit of contrast behaves as a linear system that can be described by its impulse response function. The method uses the entire wash-in and wash-out curves of both the epicardial coronary artery (input function) and the myocardium (output function). Given two assumptions (stationarity and superposition) the transfer function will predict the myocardial curve from the arterial curve. Promising results were obtained, suggesting that the method may be more accurate than conventional indicator dilution and appearance time variables while obviating the requirement for gated power injection of contrast.

All these techniques have their limitations, particularly when used in a clinical setting. Many are sensitive to the effects of confounding variables such as injection technique and the effects of cardiac and respiratory cycle on density measurements, requiring relatively prolonged breath holding. Despite the development of three dimensional reconstruction (see below in the section on linear programming techniques) none of the methods can yet provide tomographic data.

\section{Temporal resolution}

Methods that rely on the accumulation of tracer cannot assess the second to second variations in perfusion that can be recorded by arterial inflow of venous outflow methods described above. They require at least a single circulation time (10-30 seconds) for tracer distribution, or 5-20 minutes for inert gas saturation or desaturation to occur.

\section{Spatial resolution}

Methods that measure arterial blood velocity or assess venous drainage can be used to assess rapid changes in flow but they have a poor spatial resolution. The resolution is defined by the myocardial segment subtended by the artery (inflow methods) or great cardiac vein or coronary sinus (outflow methods). The resolution of methods used to assess tissue perfusion depends on the tracer and detector combination used and on the availability of tomographic reconstruction to provide information in three spatial dimensions. involve the single photon emitters. Thallium201 has several disadvantages: its long halflife limits the dose that can be safely given to a patient and its main emission is of photons with relatively low energy. These factors combine to produce low resolution scintigrams with a low signal to noise ratio. Technetium$99 \mathrm{~m}$ emits photons of $140 \mathrm{keV}$ and hence is well suited to scintillation cameras. There is less tissue attenuation and greater image resolution. Technetium-99m has a shorter half life $(6 \mathrm{~h})$ which permits higher activity to be administered safely. Two groups of compounds have been developed for use in medical imaging - the isonitriles and the substituted oximes. Technetium-labelled 2methoxy-isobutyl-isonitrile ( ${ }^{99 m}$ Tc-MIBI) has a first pass myocardial extraction of $40 \%$. Uptake seems to be by passive diffusion into the cytosol and is proportional to blood flow. Unlike ${ }^{201}$ thallium there is no significant washout or redistribution. Technetium-99m teboroxime is a neutral lipophilic molecule that has a higher first pass extraction fraction $(85 \%)$ but a very short half life within the myocardium. Image acquisition must therefore be performed rapidly but early repeat studies are possible. Distribution is flow dependent and may be less affected by cellular dysfunction than ${ }^{99 m}$ Tc-MIBI. ${ }^{40}$

\section{TOMOGRAPHY}

Planar thallium imaging, ${ }^{133}$ xenon washout, and videodensitometric methods are all limited because the three dimensional object under investigation is "projected" onto a two dimensional surface so that it is difficult to determine the relative depths of objects in the image because overlapping structures are superimposed. From a series of projection images taken from different angles around the heart, it is possible to reconstruct the three dimensional information of the scanned object, and so generate a tomogram. Both positron emission and single photon emission tomography provide information on the distribution of perfusion in three dimensions. Nevertheless neither of these techniques has sufficient spatial resolution to assess transmural differences in perfusion.

\section{THREE DIMENSIONAL RECONSTRUCTION FROM} BIPLANE ANGIOGRAPHY

There have been several approaches to the three dimensional reconstruction of both the coronary arterial tree and the myocardium from biplane cine angiograms. Linear programming techniques ${ }^{41}$ have been used to try to overcome the limitations of planar imaging during coronary angiography and videodensitometric assessment of perfusion. To limit the large number of feasable three dimensional reconstruction solutions from the biplane data, information from the geometry of the epicardial and endocardial boundaries was used together with a computer model of the shape of the myocardium. ${ }^{42}$ The three dimensional reconstruction of the coronary arterial tree has also been investigated using 
the $x$ ray projection matrices calculated from a cube phantom filmed in the same projections. ${ }^{32}$ With the intracoronary vascular volume accurately measured, coronary flow can be determined.

\section{Absolute or relative perfusion}

Methods that assess arterial inflow or venous outflow express flow in volume per unit time: the amount of muscle supplied or draining the area remains undetermined. Flow measurements based on inert gas diffusion are expressed as flow per unit muscle mass (because muscle mass cannot be determined by the technique). Though the absolute amount of tracer is not usually measured, flow can be calculated if the partition coefficient is known. Some videodensitometric methods that are based on transit time and that use indicator dilution express flow in volume per time: however, the method is simplified if only relative flow is measured.

To measure absolute perfusion by means of the first pass distribution model it must be possible to measure the absolute concentration of tracer. The percentage of photons emitted from a single photon source (such as thallium) that reach a scintillation camera is dependent on scatter attenuation of the body and the distance between the photon source and detector. Because the attenuation path travelled by the photons cannot be measured the absolute concentration of thallium remains unknown and the technique only allows measurement of relative perfusion. Positron emission tomography, however, can be used to measure absolute concentration of the tracer. Coincidence detection of annihilation photons allows the photon's path to be defined so that its attenuation can be calculated.

A positron-emitting isotope is characterised by an excess number of protons. If the excess proton decays to a neutron, a positron (the antiparticle of the electron) and a neutrino are emitted. Positrons emitted in a tissue lose kinetic energy in collisions with atoms and typically travel 1 to $3 \mathrm{~mm}$ before coming to rest, usually within $10^{-9}$ second. The positron then combines with an electron in an "annihilation reaction", so that their mass is converted to energy, which takes the form of two $511 \mathrm{keV}$ photons travelling in approximately opposite directions.

With paired detectors around a patient, this simultaneous photon production can be detected. Instead of the rotating scintillation camera used to detect single photon emission, the patient is surrounded by a fixed circular array of stationary scintillation detectors that currently allows up to about 21 simultaneous tomographic images to be acquired. A transmission image is acquired first, to be used for attenuation correction. The positron emitter is then injected intravenously and, after an appropriate time interval, data from annihilation photons are acquired. After analysis the projection images are reconstructed by filtered back projection to create a tomographic representation of tracer concentration in the myocardium.

\section{Newer techniques}

None of the techniques described above can distinguish differences in the transmural distribution of perfusion. Studies in animals have shown that alterations in the perfusion of different layers of the myocardium are of prime importance in understanding the regulation of the coronary circulation, the subendocardium being most vulnerable to reductions in epicardial vessel perfusion or increases in myocardial oxygen demand. The spatial resolution of magnetic resonance imaging, echocardiography, and $x$ ray computed tomography is theoretically sufficient to distinguish such transmural variation in perfusion.

\section{MAGNETIC RESONANCE IMAGING}

The development of rapid scan sequences and the use of paramagnetic compounds, such as gadolinium-diethylenetriaminepentaacetic acid (gadolinium-DTPA), as contrast agents has led investigators to explore the possibility of measuring myocardial perfusion with magnetic resonance imaging. Gadolinium-DTPA has an extracellular distribution and shortens both the longitudinal (T1) and transverse (T2) relaxation times, with the former predominating at low dose. The magnitude of this change is dependent on the magnetic field strength and the concentration of the paramagnetic agent. Encouraging results have been reported with a modified Kety equation ${ }^{43}$ and first pass distribution ${ }^{44}$ but the difficulty in relating signal intensity to absolute gadolinium-DTPA concentration in vivo needs to be overcome before measurement of absolute myocardial perfusion is possible.

\section{CONTRAST ECHOCARDIOGRAPHY}

Microbubbles, produced by manually agitating a solution, have been used to try to assess myocardial perfusion after direct intracoronary injection. The most important methodological difficulties include the variable relation between contrast concentration and signal intensity, the difficulty in calibrating signal intensity, and the variable stability of current contrast agents which leads to unpredictable pulmonary transit. As a result most studies have used intracoronary injections of contrast, though there are encouraging data on the safety and stability of newer contrast agents such as sonicated albumin microspheres, ${ }^{45}$ which successfully opacify the myocardium after intravenous injection.

\section{ULTRAFAST X RAY COMPUTED TOMOGRAPHY} Rapid exposure times in $x$ ray computed tomography have been achieved by a design that obviates the need for moving parts in the gantry of the scanner. Instead of a rotating $x$ ray source, an electron beam is focused and deflected so as to sweep a stationary tungsten target. This creates a rapidly rotating fan of 
$x$ rays, allowing cross sectional images to be obtained in up to $50 \mathrm{~ms}$. Without the problem of motion artefact, the concentration of radio-opaque contrast (used as a tracer) can be measured and absolute perfusion derived from first pass distribution principles. This method has been validated against microspheres in $\operatorname{dogs}^{4647}$ and relative perfusion has been validated against single photon emission tomography in humans. ${ }^{48}$ Probably because of variable tracer extraction ${ }^{19}$ the method underestimates flows above about 1.5 $\mathrm{ml} / \mathrm{g} / \mathrm{min}$, though modifications to the basic algorithm are being explored and provisional results are encouraging. ${ }^{49}$ Work in which aortic root injections of contrast were used ${ }^{5051}$ suggests that these measurements may not be liable to under estimation of high flows and may be able to assess differences in subendocardial to subepicardial perfusion.

\section{Patient considerations}

All methods are invasive. Some, such as intracoronary Doppler ultrasound, xenon-133 clearance, and videodensitometry involve catheter manipulation in coronary arteries; and electromagnetic probes require surgical dissection of the vessel. All other methods require venous access. Coronary sinus techniques require catheter manipulation during $x$ ray screening, while tracers for single photon and positron emission tomography are given into a peripheral vein. Pulmonary extraction of contrast agents used in echocardiography has necessitated intracoronary injection, though stable agents are being developed for intravenous injection. Ultrafast computed tomography requires either a central venous cannula (for the bolus of contrast delivered at a high flow rate or an intra-aortic root injection. Magnetic resonance techniques also require a rapid bolus of contrast to be delivered intravenously.

Most methods involve exposing the patient to ionising radiation. Arterial velocity and coronary sinus techniques require $x$ ray screening to assess catheter position. Single photon and positron emission methods and radiolabelled xenon result in exposure after the administration of a radioactive substance. Videodensitometry and $x$ ray computed tomography use an $x$ ray source to generate images. Only echocardiography and magnetic resonance imaging are free from this disadvantage. At present there is no evidence to suggest that exposure to ultrasound or to the combination of fixed strong and rapidly changing magnetic fields and radiofrequency transmissions required for magnetic resonance imaging is detrimental to humans or other animals.

\section{Conclusions}

Currently no method is able to assess absolute myocardial perfusion with high temporal and spatial resolution in humans. The choice of technique therefore must depend on the type of study being performed and ques- tions being asked. In general rapid changes in flow cannot be assessed by methods that use tracers, though such techniques have the advantage of higher spatial resolution. Development of newer methods may soon allow the differential perfusion of the endocardial and epicardial layers to be explored in humans.

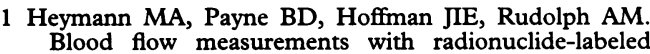
particles. Prog Cardiovasc Dis 1977;20:55-79.

2 Cole JS, Hartley CJ. The pulsed Doppler coronary artery catheter, preliminary report of a new technique for measuring rapid changes in coronary artery flow velocity in man. Circulation 1977;56:18-25.

3 Wilson RF, Laughlin DE, Ackell PH, Chilian WM, Holida MD, Hartley CJ, Armstrong ML, Marcus ML, White CW. Transluminal, subselective measurement of coronary artery blood flow velocity and vasodilator reserve in man. Circulation 1985;72:82-92.

4 Doucette JW, Corl PD, Payne HM, et al. Validation of a Doppler guidewire for intravascular measurement of coronary artery flow velocity. Circulation 1992; 85:1899-911.

5 Mancini GBJ. Applications of digital angiography to the coronary circulation. In: Marcus ML, Schelbert HR, Skorton DJ, Wolf GL, eds. Cardiac imaging: a companion to Braunwald's Heart Disease. Philadelphia: WB ion to Braunwald's H.

6 Wilson RF, Wyche K, Christensen BV, Zimmer S, Laxson DD. Effects of adenosine on the human coronary arterial circulation. Circulation 1990;82:1595-606.

7 Gould KL, Kirkecide RL, Buchi M. Coronary flow reserve as a physiologic measure of stenosis severity. $\mathcal{f}$ Am Coll Cardiol 1990;15:459-74.

8 Sitomer J, LeFree MT, Anselmo EG, Simon SB, Mancini GBJ. Computer image-guided gantry positioning for optimization of quantitative coronary arteriography. $\mathrm{Am}$ f Cardiac Imag 1989;3:191-8.

9 Katritis D, Lythall DA, Anderson MH, Cooper IC, Webb-Peploe MM. Assessment of coronary angioplasty by an automated digital angiographic method. Am Heart F $1988 ; 116: 1181-7$

10 Mancini GBJ. Quantitative coronary arteriographic methods in the interventional catherization laboratory: an update and perspective. $\mathcal{F ~} \mathrm{Am}$ Coll Cardiol 1991;17: 23B-33B.

11 Hulzebosch AA, Slump CH, Viergever MA. Threedimensional reconstruction of stenosed coronary artery segments with the assessment of the flow impedance. In f Cardiac Imag 1990;5:135-143.

12 Ganz W, Tamura K, Marcus HS, Donoso R, Yoshida S Swan HJC. Measurement of coronary sinus blood flow by continuous thermodilution in man. Circulation 1971;44:181-95.

13 Mathey DG, Chatterjee $\mathrm{K}$, Tyberg JV, Lekven J, Brundage B, Parmley WW. Coronary sinus reflux: a source of error in the measurement of thermodilution coronary sinus flow. Circulation 1978;57:778-86.

14 Ludman PF, Maseri A, Clark P, Davies GJ. Effects of calcitonin gene-related peptide on normal and atheromatous vessels and on resistance vessels in the coronar circulation in humans. Circulation 1992;84:1993-2000.

15 Sapirstein LA. Regional Blood flow by fractional distribution of indicators: Am $\mathcal{F}$ Physiol 1958;193:161-8.

16 Weich HF, Strauss W, Pitt B. The extraction of thallium201 by the myocardium. Circulation 1977;56:188-91.

17 Schelbert HR, Phelps ME, Huang S-C, MacDonald NS, Hansen H, Selin C, Kuhl DE. N-13 ammonia as an indicator of myocardial blood flow. Circulation 1981;
63:1259-72. Goldstein RA, Mullani NA, Marani SK, Fisher DJ, Gould $\mathrm{KL}$, O'Brien HAJ. Myocardial perfusion with rubidium82. II. Effects of metabolic and pharmacologic intervention. $\mathcal{f} \mathrm{Nucl}$ Med 1983;24:907-15.

19 Canty JM, Srinivasan G. First-pass extraction of nonionic contrast is dependent upon vasomotor tone; estimates at contrast is dependent upon vasomotor tone; estimates at
rest and following pharmacological vasodilatation using fast CT [abstr]. Circulation 1991;84 suppl II:678.

20 Mullani NA, Goldstein RA, Gould KL, Fischer DJ, Marani SK, O'Brien HA. Myocardial perfusion with rubidium-82. 1, Measurement of extraction fraction and flow with external detectors. F Nucl Med 1983, 24:898-906.

21 Nienaber CA, Ratib O, Gambhir SS, Krivokapich J, Huang S-C, Phelps ME, Schelbert HR. A quantitative assessment of regional blood flow in canine myocardium derived noninvasively with $\mathrm{N}-13$ ammonia and dynamic positron emission tomography. $\mathcal{F}$ Am Coll Cardiol 1991; 17:260-9.

22 Bergman SR, Fox KAA, Rand AL, McElvany KD, Welch MJ, Markham J, Sobel BE. Quantification of regional myocardial blood flow in vivo with $\mathrm{H}_{2}{ }^{15} \mathrm{O}$ water. Circulation 1984;70:724-33.

23 Eckenhoff JE, Hafkenschiel JH, Harmel $\mathrm{MH}$, Goodale WT, Lubin M, Bing RJ, Kety SS. Measurement of WT, Lubin M, Bing RJ, Kety SS. Measurement of Physiol 1948;152:356-64. 
24 Kety SS, Schmidt CF. The determination of cerebral blood flow in man by the use of nitous oxide in low concentrations. Am F Physiol 1945;143:53-66.

25 Schanzenbächer P, Klocke FJ. Inert gas measurements of myocardial perfusion in the presence of heterogeneous flow docur

26 Kety SS. Measurement of regional circulation by the local clearance of radioactive sodium. Am Heart $\mathcal{f} 1949 ; 38$ : clearan

27 Cannon PJ, Dell RB, Dwyer EMJr. Measurement of regional myocardial perfusion in man with ${ }^{133}$ Xenon and a scintillation camera. $\mathcal{F}$ Clin Invest 1972;51:964-77.

28 Maseri A. Radioactive tracer techniques for evaluating coronary flow. In: Yu PN, Goodwin JF. Progress in cardiology. Philadelphia: Lea \& Febiger, 1976;141-68.

29 Morgan SM, Fischer JD, Horwitz LD. Validation of regional myocardial flow measurements with scintillation camera detection of xenon-133. Invest Radiol 1978;13:132-7.

30 Spiller P, Schmiel FK, Politz B, Block M, Fermor U, Hackbarth W, Jehle J, Korfer R, Pannek H. Measurements of systolic and diastolic flow rates in the coronary artery system by $x$-ray densitometry. Coronary artery system

31 Kruger RA. Estimation of the diameter of and iodine concentration within blood vessels using digital radiography devices. Med Phys 1981;8:652-8.

32 Guggenheim N, Chappuis F, Suilen C, Doriot PA, Dorsaz PA, Descouts P, Ruithauser W. 3D-reconstruction of coronary arteries in view of flow measurement. Int $\mathcal{f}$ Cardiac Imag 1992;8:265-72.

33 Foerster J, Link DP, Lantz BMT, Lee G, Holcroft JW, Mason DT. Measurement of coronary reactive hyperaemia during clinical angiography by video dilution technique. Acta Radiol 1981;22:209-16.

34 Gurley JC, Nissen SE, Elion JL, Booth DC, DeMaria AN. Determination of coronary flow reserve by digital subDetermination of coronary flow reserve by digital subtraction angiography: validation of a practical method
not requiring power injection or electrocardiographic not requiring power injection or electroc

35 Vogel R, LeFree M Bates E, O'Neill W, Foster R, Kirlin P, Smith D, Pitt B. Application of digital techniques to selective coronary arteriography: use of myocardial contrast appearance time to measure coronary flow reserve. Am Heart f 1984;107:153-64.

36 Nissen SE, Elion JL, Booth DC. Value and limitations of computer analysis of digital subtraction angiography in the assessment of coronary flow reserve. Circulation 1986;73:562-71.

37 Hodgson JMcB, Legrand V, Bates ER, Mancini GB, Aueron FM, W. OW, Simon SB, Beauman GJ, LeFree MT, Vogel RA. Validation in dogs of a rapid digital angiographic technique to measure relative coronary blood flow during routine cardiac catheterisation. $A m \mathcal{F}$ baod flow during routine

38 Ikeda H, Koga Y, Utsu F, Toshima H. Quantitative evaluation of regional myocardial blood flow by videodensitometric analysis of digital substraction coronary arteriography in humans. $\mathcal{f} \mathrm{Am}$ Coll Cardiol 1986;8: 809-16.
39 Eigler NL, Pfaff M, Zeiher A, Whiting JS, Forrester JS Digital angiographic impulse response analysis of regional myocardial perfusion: linearity, reproducibility, accuracy, and comparison with conventional indicator dilution curve parameters in phantom and canine models. Circ Res 1989;64:853-66.

40 Leppo JA, DePuey EG, Johnson LL. A review of cardiac imaging with sestamibi and teboroxime. $f$ Nucl Med imaging with ses

41 Slump CH, Gerbrands JJ. A network flow approach to the reconstruction of the left ventricle from two projections. Comp Graph Im Proc 1982;18:151-63.

42 Dumay AC, Zijdenbos AP, Pinto IM, Gerbrands JJ, Roos C, Serruys PW, Reiber JH. Developments towards the slice-wise three-dimensional reconstruction of the distribution of the contrast perfusion in the myocardial muscle from biplane angiographic views. Int $\mathcal{f}$ Card Imaging 1990;5:213-24.

43 Diesbourg LD, Prato FS, Wisenberg G, Drost DJ, Marshall TP, Carroll SE, O'Neill B. Quantification of myocardial blood flow and extracellular volumes using a bolus injection of Gd-DTPA: kinetic modeling in canine ischemic disease. Magn Reson Med 1992;23: 239-53.

44 Manning JW, Atkinson DJ, Grossman W, Paulin S, Edelman RR. First-pass nuclear magnetic resonance imaging studies using gadolinium-DTPA in patients with coronary artery disease. $\mathcal{F} \mathrm{Am}$ Coll Cardiol 1991; 18:955-65.

45 Feinstein SB, Cheirif J, Ten Cate FJ, Silverman PR, Heidenreich PA, Dick C, Desir RM, Armstrong WF, Quinones MA, Shah PM. Safety and efficacy of a new transpulmonary ultrasound contrast agent: initial multicentre clinical results 7 Am Coll Cardiol 1990;16: 316-24.

46 Wolfkiel CJ, Ferguson JL, Chomka EV, Law WR, Labin IN, Tenzer ML, Booker M, Brundage BH. Measurement of myocardial blood flow by ultrafast Measurement of myocardial blood flow by ultrafast

47 Rumberger JA, Feiring AJ, Lipton MJ, Higgins CB, Ell SR, Marcus ML. Use of ultrafast computed tomography to quantitate regional myocardial perfusion: a preliminary report. $\mathcal{f}$ Am Coll Cardiol 1987;9:59-69.

48 Ludman PF, Coats AJS, Poole-Wilson PA, Underwood SR, Rees S. Measurement of myocardial perfusion in humans by ultrafast $x$ ray computed tomography: validation by comparison with adenosine thallium tomography [abstr]. Br Heart f 1992;68:106P.

49 Wolfkiel CJ, Law WR, Jelnin V, Claudio J, Krahmer RL, Ferguson JL. Measurement of elevated myocardial blood flows with ultrafast computed tomography and intravenous contrast medium [abstr]. Circulation 1992; intraven 165 .

50 Weiss RM, Santos RM, Ginkel DL, Grover-McKay M, Marcus ML. Quantitation of the subendocardial to Marcus ML. Quantitation of the subendocardial to
subepicardial perfusion ratio with cine CT [abstr]. Circulation 1989;80(suppl II):109.

51 Wang T, Wu X, Chung N, Ritman E. Myocardial blood flow estimated by synchronous multislice, high speed computed tomography. IEEE Trans Med Imaging 1989; 8:70-7. 